\title{
Comparative Analysis of the Performance of Boats According to Shapes
}

\author{
Chong-hoon Lee ${ }^{1}$ and $\mathrm{Ki}$-jeong $\mathrm{Nam}^{2 *}$ \\ ${ }^{1}$ Department of Sports Science Seoul National University of Science \& Technology, \\ Seoul, Korea \\ ${ }^{2}$ Department of Physical Education Seoul National University, Seoul, Korea \\ ${ }^{1}$ leejh36@snut.ac.kr, ${ }^{2}$ rugg3@snu.ac.kr \\ *corresponding Author
}

\begin{abstract}
The present study compared the performances of three types of boats of different shapesto develop boats that are more efficient for the activation of water leisure. Three types of inflatable boats were used in the experiment: kayak boat A, which is relatively wide; kayak boat $B$, which is relatively long; and boat $C$, in which a frame was installed. The paddles used in the experiment were $230 \mathrm{~cm}$ long and made of plastic by the same company, and six healthy male university students participated in the experiment. In the experiment, boat $C$, which is an inflatable boat with an added frame, showed the highest straight sailing speed, leading to the conclusion that the straight sailing performance of boat $C$ is superior to that of boats $A$ and Bwithout any frame. Boat $C$ was greater in stability and rotation capacity compared to the other boats, although the differences were not statistically significant. The reason why boat $C$, which is a framed boat, could sail faster than other boats is considered to be based on the fact that the experimental subjects psychologically judged that boat $C$ was safe because its lateral rolling was lesser than that of the other two boats and it took stronger and faster stroke motions.
\end{abstract}

Keywords: Kayak boats, inflatable, IMU

\section{Introduction}

Among water leisure sporting events, kayaking is an activity that can be utilized first for the activation of the water leisure sport market, because kayaking equipment is cheaper than other events are and it can be easily used. In addition, kayaking is an activity generally known to the public, where the participants sit in the boat with their legs extended in the direction of the movement of the boat and they make bi-directional motions of repeatedly pulling a paddle attached with blades on both ends (Michael, Smith, \& Rooney, 2009; Ryu \& Lee, 1997; Lee, Nam, \& Ryu, 2012). Such repetitive rowing motions are highly effective for a whole body exercise that reinforces cardio pulmonary functions, increases the strength of the muscles in the upper body, waist, abdomen, and legs of humans, and improves the ability to control the arms and legs. Kayaking can be considered a highly popular water leisure sport and it enables everybody to enjoy torrent tours easily and safely after simply learning some paddling skills.

Studies regarding the resistance and thrust occurring on boats and water surfaces (Jackson, 1995; Baudouin\& Hawkins, 2002; Pendergast, Mollendorf, Zamparo, Termin, Bushnell, \& Paschke, 2005) indicate that boat speed is higher when the volume of the boat immersed in the water is smaller and when participants with higher levels of skills make faster stroke motions. A study conducted by Lee, Park, and Nam (2013) comparatively analyzed hard-shell boats and inflatable boats and indicated that the performances of inflatable boats were greater because the straight sailing speed of inflatable boats was higher and because the volume of the inflatable boats immersed in 
the water was smaller than that of hard-shell boats. However, boats should not be concluded to be excellent only based on a high straight sailing speed. As kayaks are not made to improve athletic performance but are made for leisure; along with straight sailing ability, safety should be also brought to the focus. That is, excellent boats should be made considering both straight sailing ability and safety. In the present study, to design excellent kayaks considering the aforementioned, three different types of boats will be comparatively analyzed, placing emphasis on safety and straight sailing ability.

The purpose of the present study is to analyze comparatively differences in the performances of two types of inflatable kayaks and one type of inflatable framed kayak and to evaluate the boats to determine which is more efficient and safer.

\section{Method}

\subsection{Participants}

To compare and evaluate the performances of three types of boats, six general male university students participated in the present study. All study participants were limited to healthy males who had no musculoskeletal system disease over that last six months so they had no problem in performing forward stroke motions in a kayak. In addition, before the present experiment, the experimental procedure was sufficiently explained orally to the study participants and only those who voluntarily agreed to participate and who completed a written agreement thereafter participated in the experiment.

\subsection{Experimental Tool}

Three types of inflatable kayaks were used in the present study. Detailed information on the boats is as shown in <Table 1$\rangle$.

Table 1. Detailed Information on Individual Kayaks

\begin{tabular}{llll}
\hline & Boat A & Boat B & Boat C \\
\hline Country of origin & South Korea & South Korea & South Korea \\
\hline Manufacturer & W Company & W Company & W Company \\
\hline Length & $3.35 \mathrm{~m}$ & $3.80 \mathrm{~m}$ & $3.35 \mathrm{~m}$ \\
\hline Width & $0.95 \mathrm{~m}$ & $0.70 \mathrm{~m}$ & $0.80 \mathrm{~m}$ \\
\hline Capacity & $200 \mathrm{~kg}$ & $193 \mathrm{~kg}$ & $113 \mathrm{~kg}$ \\
\hline Weight & $15 \mathrm{~kg}$ & $12.5 \mathrm{~kg}$ & $12.0 \mathrm{~kg}$ \\
\hline
\end{tabular}

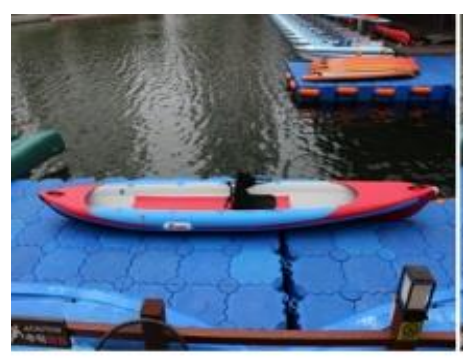

A boat

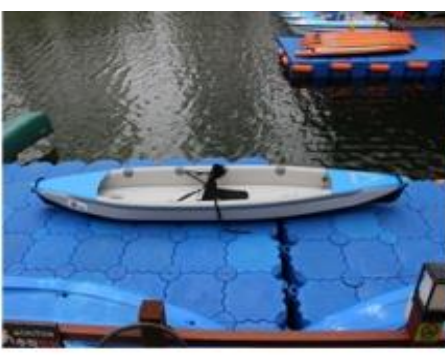

B boat

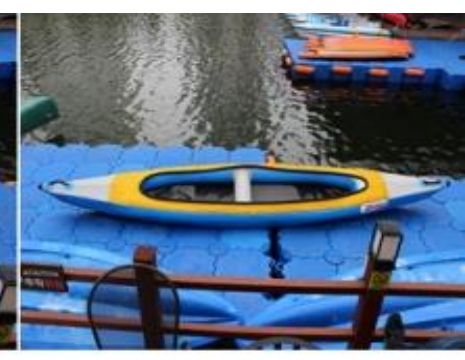

C boat

Figure 1.Three Types of Kayak Boats used in the Study 
As can be seen in 〈Table 1>, the difference between the two types of inflatable boats is that kayak boat A is relatively wider, while kayak boat B is relatively longer. In addition, boat $\mathrm{C}$ is an inflatable boat installed with a frame. Paddles used in the experiment are 230 $\mathrm{cm}$ long and made of plastic by the same company. <Figure 1> shows the boats used in the study.

An inertial sensor system (MyoMotion, Noraxon, USA) was used to analyze boat performance. This system uses acceleration sensors, gyro sensors, and earth magnetic field sensors and can calculate the accelerations and kinematic variables of individual sensors. The size of these sensors is $3.5 \mathrm{~cm} \times 5.0 \mathrm{~cm} \times 2.0 \mathrm{~cm}<$ Figure 2>. Data were collected directly with a computer through receivers in the Wi-fi wireless digital communication mode, at a sampling rate set to $200 \mathrm{~Hz}$.

\subsection{Experimental Procedure}

The purpose of the present study is to analyze comparatively the performances of three types of boats. To this end, study participants participated in the experiment after hearing explanations of the experiment and completing a written agreement. The experiment was conducted in Central Park, located in Songdo, Incheon, and boat performances were evaluated in fresh water with no effect of flow velocity. All participants had trial rides on the boats to have sufficient practice and preparation for the experiment, and the experiments started when all participants performed stretching and warm-up exercises to become physically ready for participation. Sensors were attached to the experimental subjects and the boats, and the positions of the grips to hold paddles were set to distances that were most preferred by the experimental subjects. The entire distance for the performance of motions was approximately $30 \mathrm{~m}$. The section in which the highest straight sailing speed was shown after departure and the section in which turning motions were performed after straight sailing were set to the analysis sections. The experimental subjects performed stroke motions at their full speed immediately after the starting signal. After completing one round, the experimental subjects had a rest for at least five minutes to begin the next round after completely recovering their physical strength. The types of boats were randomly selected for the experimental subjects.

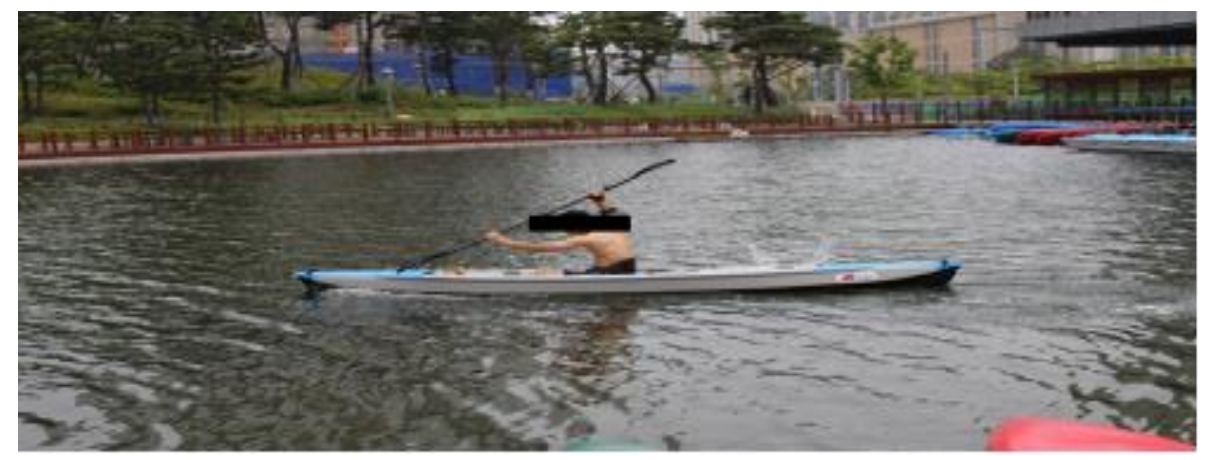

Figure 2. A View of the Experiment

\subsection{Data Analysis}

The performances of the boats were separately evaluated for thrust, stability, and rotation capacity. First, the speeds of the boats were calculated to analyze thrust, which was done by integrating the acceleration values on the inertial sensors attached to the boat and the stability of the boat by calculating the lateral ROM angles based on the signals generated by the inertial sensors attached to the boats. The rotation capacity of the boats was analyzed by calculating the average angular rotation velocity of the boats based on the inertial sensors. 


\subsection{Statistical Analysis}

Paired t-tests were conducted to identify differences in boat performances and players' performance capabilities between the two types of inflatable kayaks using SPSS 18.0. The significance level was set to $\alpha=.05$.

\section{Results}

Table 2 shows the variables calculated to evaluate the performances of the three boat types.

Table 1. Boat Speeds, Angular Velocities, and Lateral Rolling Angles

\begin{tabular}{llll}
\hline & A & B & C \\
\hline Boat speed $(\mathrm{m} / \mathrm{s})$ & $1.57 \pm 2.35$ & $1.62 \pm 1.87$ & $1.87 \pm 0.77$ \\
\hline Boat angular velocity $(\% / \mathrm{s})$ & $12.78 \pm 5.41$ & $10.87 \pm 6.27$ & $13.01 \pm 5.54$ \\
\hline Lateral rolling angles $\left({ }^{\circ}\right)$ & $12.47 \pm 6.84$ & $12.23 \pm 5.29$ & $11.87 \pm 4.08$ \\
\hline
\end{tabular}

\section{Boat Speed}

The maximum straight sailing speeds of the boats were calculated. Higher values can be said to be associated with more excellent straight sailing capacity. Boat $\mathrm{C}$ showed statistically significant differences from boats $\mathrm{A}$ and $\mathrm{B}$. According the to the results of analysis, the speed of boat $\mathrm{C}$ was the highest and the speeds of boats $\mathrm{A}$ and $\mathrm{B}$ were not statistically significantly different.

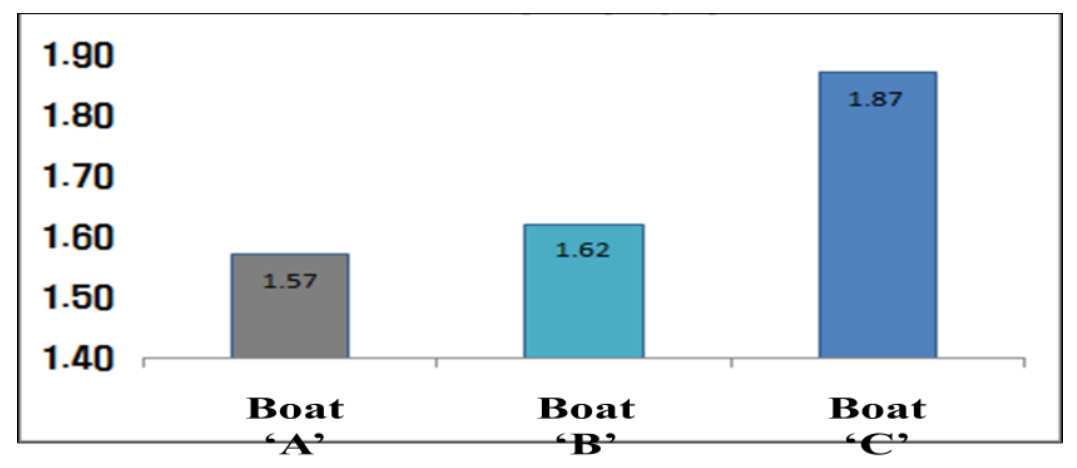

Figure 3. Straight Sailing Speeds of the Boats

\section{Lateral Rolling Angles}

This variable indicates the degree of lateral rolling of the boats, and lower values of this variable can indicatea greater stability. According to the results of analysis, the lateral rolling angle of boat $\mathrm{C}$ was the smallest, but the differences among the boats were not statistically significant. 


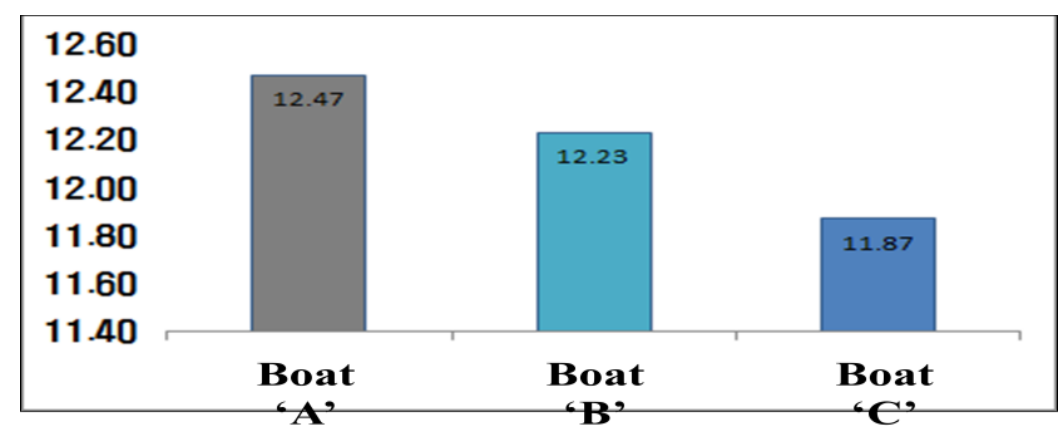

Figure 4. Boat Stability Variable

\section{Angular rotation velocity}

The angular rotation velocity of the boats is the maximum angular velocity value when a boat turns, and higher values of angular rotation velocity indicate a greater rotation capacity. According to the results of the analysis, the angular velocity of boat $\mathrm{C}$ was the highest and this can be the basis for a conclusion that boat $\mathrm{C}$ turns the quickest. Although boat $\mathrm{A}$ showed a tendency to turn faster than boat $\mathrm{B}$, differences in angular velocities among all boats were not statistically significant.

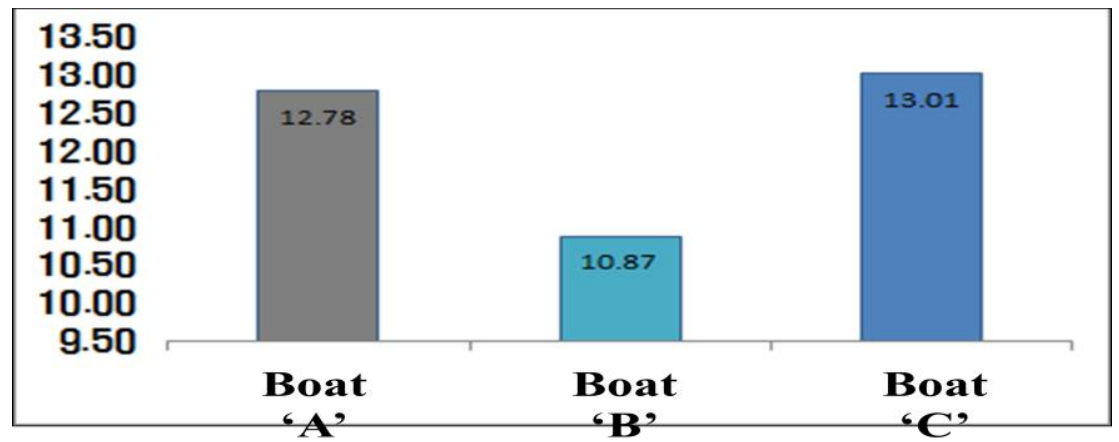

Figure 5. Boats' Rotation Capacity Variable

\section{Discussion and Conclusion}

In the case of athletic performances in water sports, such as kayaking, maintaining a constant boat speed is important (Michael, et al., 2009; Plagenhoef, 1979; Lee, et al., 2012), and to increase boat speeds, more stroke motions in the same period or longer paddles are necessary (Baudouin\& Hawkins, 2004). Limonta, et al., (2010) examined differences in the kinematic variables in paddling motions among three groups: an elite player group, a general intermediate person group, and a beginner group with ergometers in kayaks. They reported that the elite player group showed higher values than other groups in paddling distance, which is an indicator of sport performance capability, and it showed laterally symmetric motion patterns. In the present study, boat $\mathrm{C}$, which is an inflatable boat with an added frame, showed the highest straight sailing speed, so it can be concluded that the straight sailing performance of boat $\mathrm{C}$ is greater than that of boats $\mathrm{A}$ and $\mathrm{B}$, which are inflatable boats without any frame. Although boat $\mathrm{C}$ was greater than other boats in stability and rotation capacity, the differences were not statistically significant. The reason boat $\mathrm{C}$, which is a framed boat, could sail faster than other boats is considered to be that the experimental subjects psychologically judged that boat $\mathrm{C}$ was safe because its lateral rolling was smaller than that of the other two boats and it took stronger and faster stroke motions. In addition, Baudouin, et al., (2002) stated that $90 \%$ of hydrodynamic drag is determined by boat shapes and the area immersed in water, and the 
remaining $10 \%$ is determined by the air resistance related to the cross-sectional area of the stem. It can be said that boat $\mathrm{C}$ showed a higher straight sailing speed because its part immersed in water is smaller than other boats because it is lighter and smaller.

Boats A and B did not show any statistically significant differencesbetween each other, and this is considered attributable to the large differences among experimental subjects. As the experiment was conducted with general people, stroke motions were inconsistent, leading to large differences.

Consequently, boat $\mathrm{C}$, which is a framed boat, had a high straight sailing performance compared to the other two boats, and boats $\mathrm{A}$ and $\mathrm{B}$ can be said to show no differences between them.

\section{Acknowledgements}

This study was supported by the Research Program funded by the Seoul National University of Science and Technology (2015-1461).

\section{References}

[1] A. Baudouin and D. Hawkins, "A biomechanical review of factors affecting rowing performance", British journal of sports medicine, vol. 36, no. 6, (2002), pp. 396-402.

[2] A. Baudouin and D. Hawkins, "Investigation of biomechanical factors affecting rowing performance", Journal of biomechanics, vol. 37, no. 7, (2004), pp. 969-976.

[3] C.-H. Lee, K.-J. Nam and J.-J. Ryu, "The effect of the distance between the saddle and the pedal on rowing patterns and muscle activity during elite kayak players' rowing motions using ergo meters", Journal of the Korean Society of Sport Biomechanics, vol. 22, no. 1, (2012), pp. 65-73.

[4] C.-H. Lee, Y.-H. Park and K.-J. Nam, "An Analysis of the Performance Kayak and Players between Hardshelland Inflatable kayak", The Korean Journal of Physical Education, vol. 52, no. 2, (2013), pp. 531-541.

[5] E. Limonta, R. Squadrone, R. Rodano, A. Marzegan, A. Veicsteinas, G. Merati and M. Sacchi, "Tridimensional kinematic analysis on a kayaking simulator: key factors to successful performance", Sports Science Health, vol. 1, (2010), pp. 27-34.

[6] J. S. Michael, R. Smith and K. B. Rooney, "Determinants of kayak paddling performance", Sports Biomechanics, vol. 8, no. 2, (2009), pp. 167-179.

[7] D. Pendergast, J. Mollendorf, P. Zamparo, A. Termin 2nd, D. Bushnell and D. Paschke, "The influence of drag on human locomotion in water", Drag and human locomotion, vol. 32, no. 1, (2005), pp. 45-57.

[8] S. Plagenhoef, "Biomechanical analysis of Olympic flatwater kayaking and canoeing", Research quarterly, vol. 50, no. 3, (1979), pp. 443-459.

[9] J.-S. Ryu and J.-S. Lee, "Analysis of the kinematic factors of canoe stroke motions", Collection ofpapers of the Korea Institute of Sport Science, vol. 16, no. 1, (1997), pp. 1-9.

[10] P. Jackson, "Performance prediction for Olympic kayaks", Journal of Sports Sciences, vol. 13, no. 3, (1995), pp. 239-245.

\section{Authors}

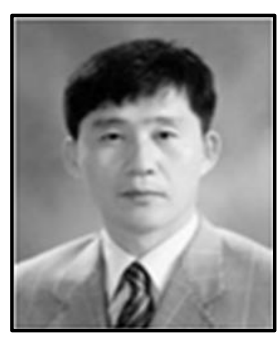

Chong-hoon Lee, He received his BS, MS in Physical Education from Seoul National University. Doctor's degree from SungKyunKwan University (School of sport science) in 1996. His major is a Sports Biomechanics. Professor, Dept. of Sports Sciences since 2000. Significant area of interest: Sport Biomechanical analysis, Development and verification of sports equipment. 


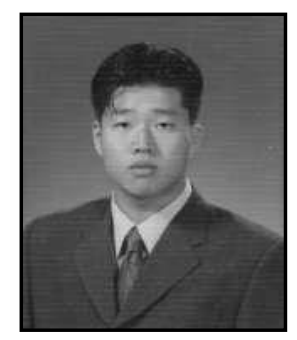

Ki-Jeong Nam, He received his BS, MS and Ph.D in Physical Education from Seoul National University. His major is a Sports Biomechanics. He is now a researcher in the Sports Biomechanics Lab at the Seoul National University and the Seoul National University of Science \& Technology.department of Biomedical Engineering. His mainresearch interests involve studying rehabilitation, injury and efficiency. 
International Journal of Bio-Science and Bio-Technology

Vol.8, No.1 (2016) 